\title{
Studies on the carbonation of Czatkowice limestone in Calcium Looping process
}

\author{
Grzegorz Tomaszewicz, Michalina Kotyczka-Morańska*, Agnieszka Plis
}

Institute for Chemical Processing of Coal, ul. Zamkowa 1, 41-803 Zabrze, Poland

Corresponding author: e-mail: mmoranska@ichpw.pl

\begin{abstract}
The growing demand for the reduction of anthropogenic $\mathrm{CO}_{2}$ emissions has stimulated the development of $\mathrm{CO}_{2}$ capture methods. One of the best capture methods comprises the calcium looping process, which incorporates calcium-based sorbents during the calcination and carbonation cycles. Czatkowice limestone may be considered to be a prospective chemical sorbent for the calcium looping process because of its formation characteristics. This paper addresses the thermogravimetric studies conducted under varying conditions of temperature and various concentrations of $\mathrm{CO}_{2}$ during the carbonation cycles. Moreover, a kinetic analysis of the carbonation stage was performed for the calcined sample at varying temperatures. The kinetic parameters for calcination and diffusion were determined. In addition, there was an increase in the concentration of $\mathrm{CO}_{2}$ with an increased carbonation conversion. The research results demonstrate that in further cycles of carbonation/calcination, the calcium sorbent reaches a higher rate of carbonation conversion with increased levels of $\mathrm{CO}_{2}$.
\end{abstract}

Keywords: calcite, limestone, calcium looping, $\mathrm{CO}_{2}$, sorbent.

\section{INTRODUCTION}

Global warming has long been recognised by the European Union as one of the most serious environmental challenges. Its main cause is believed to be the increasing concentration of $\mathrm{CO}_{2}$ in the atmosphere. It is acknowledged a priori that people are to be held accountable for the increase of the $\mathrm{CO}_{2}$ concentration in the Earth's atmosphere. This has triggered the enactment of further directives with the goal of reducing $\mathrm{CO}_{2}$ emissions. Regardless of how these official decisions are assessed, they have caused a sudden development of various technologies to address the emissions, along with the utilisation or capture and storage of $\mathrm{CO}_{2}$. These methods may be divided into either physical or chemical. The physical methods include membrane separation and adsorption. The chemical methods include the absorptive separation on solids or in solvents. Calcium looping is an absorptive method and is one of the most promising technologies for $\mathrm{CO}_{2}$ removal from post-combustion flue gas, especially because of the related processing costs ${ }^{1}$. The calcium sorbent performs a key role in this method; it functions in alternating cycles of calcination and carbonation making it possible to obtain a flux of clean $\mathrm{CO}_{2}$, which may be subsequently disposed (sequestration). Because there are various properties of limestone grades, it is observed that different effectiveness ratios of the process are caused by numerous factors. One of these factors includes the decrease of capture efficiency as the number of calcium looping cycles increases. This phenomenon is a direct consequence of sintering the sorbent active surface and the chemical deactivation resulting from a reaction with sulphur oxides $\left(\mathrm{SO}_{2}\right)$ competing in carbonation ${ }^{2-4}$. The reaction with sulphur compounds is irreversible, even though it resembles the carbonation reaction (both are heterogeneous and occur in the porous structure of the sorbent). Under the process conditions, calcium looping takes place in the small pores and covers the sorbent surface and thus prevents the carbonation reaction from occurring $^{5-8}$. The carbonation process itself proceeds in the micropores (which leads to their rapid filling), mesopores and at grain boundaries, ${ }^{9}$.
The efficiency of $\mathrm{CO}_{2}$ capture depends on multiple parameters, including diffusion, which is affected by the sorbent grain size, pore volume and structure, the area of the sorbent's actual surface, and the kinetics of the reaction ${ }^{11}$. All of these parameters are crucial for both the carbonation and calcinations processes. The alternating progress of the capture and calcination processes also triggers a reduction in the active surfaces of the particles. This reduction is due to declining microporosity, which is caused by a more dense packing of $\mathrm{CaO}$ (cubic structure) compared with the packing of $\mathrm{CaCO}_{3}$ (rhombohedral structure $)^{12} \cdot \mathrm{CO}_{2}$ capture by activated $\mathrm{CaO}$ proceeds in two stages: the preliminary stage, characterised by a very high reaction rate; and the second stage, which is slow and is a consequence of $\mathrm{CO}_{2}$ diffusion through the $\mathrm{CaCO}_{3}$ layer. Therefore, in the addressed mode of operation, the calcium looping system will only use the first stage of $\mathrm{CO}_{2}$ capture $^{13}$. It is stressed that the rapid carbonation stage depends considerably on the sorbent surface parameters. Oakkeson and Culter studied size changes in the sorbent particles and surface changes during each of the calcination and carbonation processes. During the process, they confirmed the parabolic shape of the grains and found a significant impact of $\mathrm{CO}_{2}$ partial pressure on process rate ${ }^{\mathbf{1 4}}$. The joint research by Bhatia and Perlmutter concluded that the diffusion stage was independent of $\mathrm{CO}_{2}$ pressure. They further discovered that the calcite layer formed concentric coatings in the direction of gas flow ${ }^{15}$.

In order to establish the kinetics of the $\mathrm{CaO}$ sorbent carbonation process, various models on this subject have been extensively discussed and applied in the literature, including the apparent mode ${ }^{16,}{ }^{17}$, the shrinking core model ${ }^{18,19}$, the random pore model ${ }^{15,20-22}$ and the grain $\operatorname{model}^{23,24}$.

As mentioned above, natural calcium sorbents are characterised by decreasing activity of $\mathrm{CO}_{2}$ capture over the course of the initial 20 capture cycles. In contrast, after approximately 100 cycles, the activity of the sorbents reaches an asymptotic value of between $7-15 \%$ under atmospheric pressure, with a carbonation time of 10 minutes. 


\section{MATERIAL AND METHODOLOGY}

In this research work, the impact of calcium looping parameters on $\mathrm{CO}_{2}$ capture was examined using specimens of limestone from the "Czatkowice" Limestone Mine. The samples had a grain size distribution between 0.1-0.4 mm. The $\mathrm{CaCO}_{3}$ content was $96 \%$, and the moisture content was below $0.1 \%$.

Tests of $\mathrm{CO}_{2}$ sorption on calcium sorbents were conducted using the Luxx 409 PG thermogravimetric analyser manufactured by Netzsch (Selb, Germany), which features a high-temperature furnace enabling measurements to be taken up to $1.500^{\circ} \mathrm{C}$. The specimens with a mass $\left(m_{s}\right)$ of $15.0 \pm 0.1 \mathrm{mg}$ were placed on a flat tray made of $\mathrm{Al}_{2} \mathrm{O}_{3}$. A sample temperature scheme of the process is shown in Figure 1. Each process started with a nitrogen flow rate of $25 \mathrm{ml} / \mathrm{min}$ at $25^{\circ} \mathrm{C}$. The next stage involved heating the sample at a rate of $20^{\circ} \mathrm{C} / \mathrm{min}$ with a flow rate of $25 \mathrm{ml} / \mathrm{min}$ to the calcination temperature $\left(880,900\right.$ or $\left.900^{\circ} \mathrm{C}\right)$. Calcination was conducted for 10 min. After calcination, the sample was cooled at a rate of $20^{\circ} \mathrm{C} / \mathrm{min}$ to $650^{\circ} \mathrm{C}$. The next step was carbonation. The hold time was $40 \mathrm{~min}$. The gas mixture flow rate was changed depending on the process parameters. After carbonation, the $\mathrm{CO}_{2}$ flow was stopped, and the system was heating to calcination temperature (heating rate of $20^{\circ} \mathrm{C} / \mathrm{min}$, and a $\mathrm{N}_{2}$ flow rate of $25 \mathrm{ml} / \mathrm{min}$ ). The sequence of calcination, cooling, carbonation, heating and calcination was repeated (10 times).

The research in question comprised studies on the impact of carbon dioxide concentration on sorbent activity as examined with consecutive working cycles. The gas composition for the tests consisted of $25 \%, 50 \%, 58 \%$, $67 \%$, and $75 \% \mathrm{CO}_{2}$ in $\mathrm{N}_{2}$.

The next stage was a study of the impact of calcination temperature on the carbonation of the sorbents. This was conducted at three calcination temperatures: $880^{\circ} \mathrm{C}, 900^{\circ} \mathrm{C}$ and $920^{\circ} \mathrm{C}$. The kinetic parameters from the process cycles were determined and compared with each other. The relevant calculations were performed using MathCad software.

\section{Studies and discussion of results}

One of the most interesting aspects investigated in the study of sorbent behaviour working in calcium looping is the impact of $\mathrm{CO}_{2}$ concentration on the efficiency of the capture process. To access the influence of $\mathrm{CO}_{2}$ concentration, the activity of the calcium sorbent was examined after ten consecutive working cycles at five $\mathrm{CO}_{2}$ concentrations applied during the course of carbonation. The studies comprised calcination at $900^{\circ} \mathrm{C}$ and carbonation at $650^{\circ} \mathrm{C}$. The results obtained are illustrated in Figure 2.

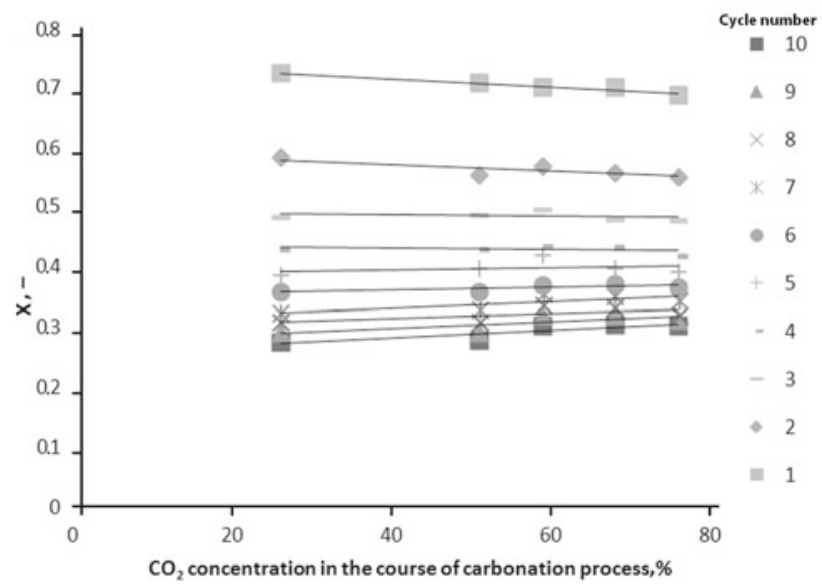

Figure 2. Correlation between carbonation conversion and $\mathrm{CO}_{2}$ concentration in the process

The numbers from 1 to 10 represent successive sorbent working cycles. In the Figure 2, an approximation conducted by the linear regression method has been matched with each of the cycles. In the first four cycles, the $\mathrm{CO}_{2}$ capture efficiently decayed with increasing $\mathrm{CO}_{2}$ concentration. This can be explained by the amplification of sintering in the $\mathrm{CO}_{2}$ atmosphere'. As noted by Chen ${ }^{25}$, carbonation rate increases considerably in presence of $\mathrm{CO}_{2}$ above the $\mathrm{CO}_{2}$ equilibrium pressure $(1.20 \mathrm{kPa})$. This implies that the process rate does not depend on lower pressures of $\mathrm{CO}_{2}$. A slight increase in the $\mathrm{CO}_{2}$ capture process efficiency for subsequent cycles with increasing $\mathrm{CO}_{2}$ partial pressure may be due to changes in the sorbent structure resulting from different partial $\mathrm{CO}_{2}$ pressure, but this requires further study. Figure 3 provides a diagram of the correlations between the slopes of matching straight lines and the cycle number. A clear upward trend in terms of the slope is evident with an increasing cycle number. Therefore, it can be concluded that this examined calcium sorbent reaches a better carbonation conversion level under increased $\mathrm{CO}_{2}$ concentrations with additional carbonation/calcination cycles.

Figure 4 shows the correlation between the extent of carbonation conversion for successive working cycles

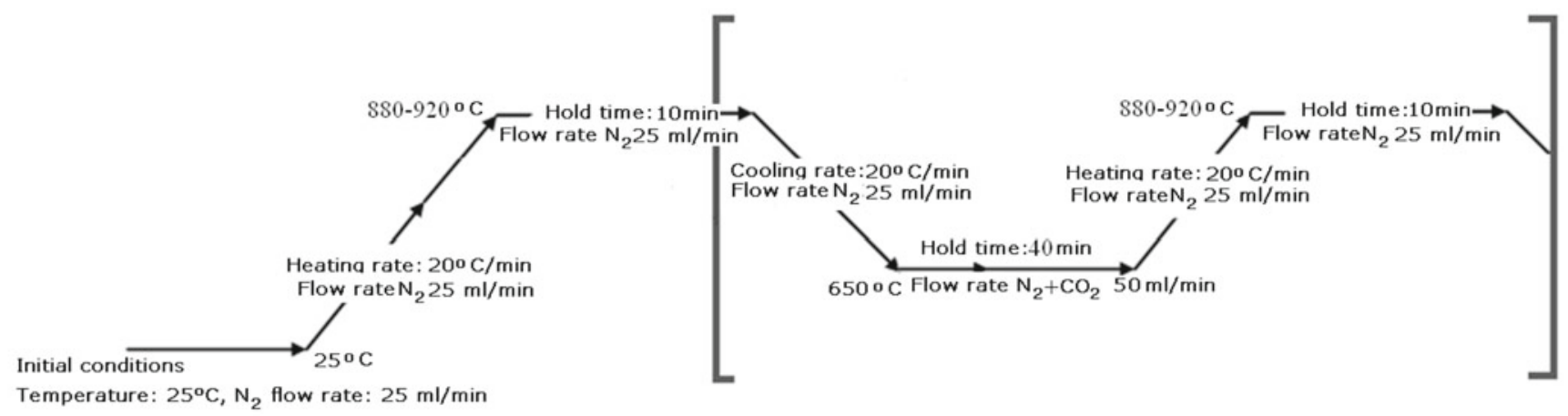

Figure 1. Sequence steps of the thermogravimetric test used in the studies. The steps enclosed in the brackets were repeated 10 times 


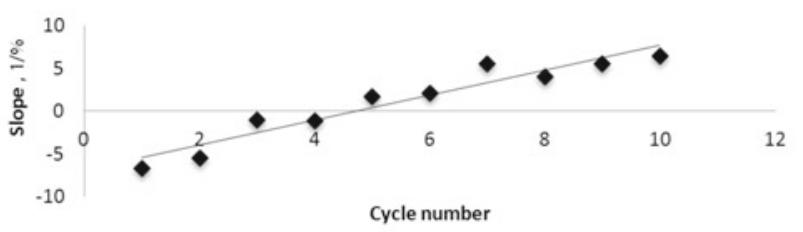

Figure 3. Correlation between the slopes of matching straight lines from Figure 2 and the sorbent working cycle number

at three calcination temperatures. Carbonation was conducted with a $67 \%$ content of $\mathrm{CO}_{2}$ in $\mathrm{N}_{2}$ at $650^{\circ} \mathrm{C}$, whereas the calcination proceeded at three temperatures: $880^{\circ} \mathrm{C}, 900^{\circ} \mathrm{C}$ and $920^{\circ} \mathrm{C}$. After the rapid and the slow (diffusion) phases, carbonation conversions are practically independent of sorbent calcination temperature. However, the activity of the sorbents calcined at $920^{\circ} \mathrm{C}$ was insignificantly lower than the activity at other temperatures. This may be related to the agglomeration of the sorbent surface, as noted by Manovic and Anthony?.

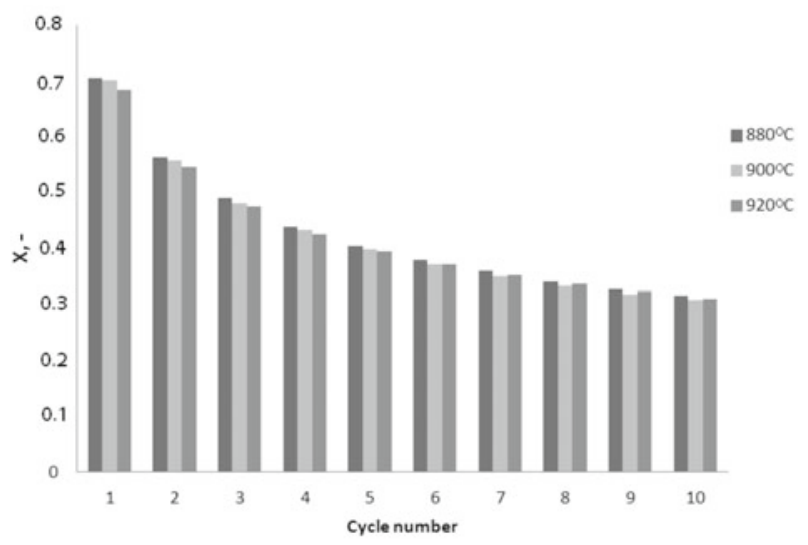

Figure 4. Correlation between carbonation conversion in consecutive working cycles and calcium sorbent calcination temperature

Another stage in the study of sorbents is the kinetic analysis of carbonation, which was performed in the first sorbent working cycle. Based on the thermogravimetric (TG) test results, a kinetic analysis of the carbonation process was conducted for a specimen that had been subject to calcination at three temperatures: $880^{\circ} \mathrm{C}$, $900^{\circ} \mathrm{C}$ and $920^{\circ} \mathrm{C}$. The carbonation process was handled in isothermal conditions at $650^{\circ} \mathrm{C}$ and at a heating rate of $20^{\circ} \mathrm{C} / \mathrm{min}$.

The conversion degree for the reaction was determined based on the following formula:

$\mathrm{X}=\left(\frac{\mathrm{m}-\mathrm{m}_{0}}{\mathrm{~m}_{0}}\right) \cdot \frac{\mathrm{M}_{\mathrm{CaO}}}{\mathrm{M}_{\mathrm{CO}}}$

where:

$\mathrm{m}-$ mass in time $\mathrm{t}[\mathrm{mg}]$,

$\mathrm{m}_{0}$ - initial sorbent mass after complete calcination [mg],

$\mathrm{M}_{\mathrm{CaO}}, \mathrm{M}_{\mathrm{CO} 2}$ - molar mass of $\mathrm{CaO}$ and $\mathrm{CO}_{2}$, respectively $[\mathrm{g} / \mathrm{mol}]$.

In the calculations below, the shrinking core model was adopted to determine the reaction rate.

The reaction rate is given by the following formula:

$\frac{\mathrm{dX}}{\mathrm{dt}}=\mathrm{k} \cdot \mathrm{f}(\mathrm{X})$ where:

$\mathrm{t}$ - time [min],

$\mathrm{X}$ - degree of conversion,

$\mathrm{f}(\mathrm{X})$ - kinetic model of the reaction,

$\mathrm{k}$ - reaction rate $[1 / \mathrm{min}]$.

The carbonation reaction proceeds in two stages ${ }^{\mathbf{1 6}, 26}$.

The first regime involves the rapid chemical reaction between the reactant gas and solid particles on the fresh $\mathrm{CaO}$ surface. A sharp interface between the product layer and the unreacted inner core of the $\mathrm{CaO}$ particle is produced. This reaction is followed by the second regime, which is a slower reaction characterised by the formation of the $\mathrm{CaCO}_{3}$ layer. This layer tends to impede the diffusion of the reactant gas. In the first stage, the reaction is kinetically controlled. After the formation of the product layer, the diffusion process controls the whole reaction.

There are several mathematical simulations in standard textbooks that propose the modelling of non-catalytic gas-solid ${ }^{27,28}$. The unreacted shrinking core model and the grain model are most commonly used for non-catalytic gas-solid reactions for non-porous and porous solid reactants, respectively. The un-reacted shrinking core model is an early model proposed for the gas-solid reaction ${ }^{29}$ and is well-explained in chemical reaction engineering textbooks. In this model, the reaction takes place at the sharp interface between the outer layer (product layer) and the inner un-reacted core of the particle. The first stage of the reaction is described by a kinetic equation, which assumes the following form:

$1-(1-\mathrm{X})^{1 / 3}=\mathrm{k}_{\mathrm{c}} \cdot \mathrm{t}$

where:

$\mathrm{k}_{\mathrm{c}}$ - surface reaction rate $[1 / \mathrm{min}]$.

The second stage involves diffusion through a film of product, which is generated on the non-reacted core of the solid phase. This film tends to limit the rate of the entire process. It is described by the following kinetic equation form:

$1-3(1-X)^{2 / 3}+2(1-X)=k_{d} \cdot t$

where:

$\mathrm{k}_{\mathrm{d}}$ - diffusion rate $[1 / \mathrm{min}]$.

The confidence interval at a significance level ( $\alpha=0.05$ ) was estimated for the reaction rates using the following formula:

$\mathrm{k}+\mathrm{t}_{(\mathrm{n}-2 ; 1-0.5 \alpha)} \cdot \mathrm{s}(\mathrm{k})>\mathrm{k}>\mathrm{k}-\mathrm{t}_{(\mathrm{n}-2 ; 1-0.5 \alpha)} \cdot \mathrm{s}(\mathrm{k})$

where:

$\mathrm{t}_{(v ; 1-0.5 \alpha)}-$ Student $t$-distribution with a significance level $\alpha$ and $v$ degrees of freedom,

$\mathrm{s}(\mathrm{k})$ - estimation error of the reaction rate, defined as:

$\mathrm{s}(\mathrm{k})=\frac{\sum_{\mathrm{i}=1}^{\mathrm{n}}\left(\mathrm{X}_{\exp _{\mathrm{i}}}-\mathrm{X}_{\mathrm{calc}_{\mathrm{i}}}\right)^{2}}{(\mathrm{n}-2) \sum_{\mathrm{i}=1}^{\mathrm{n}}\left(\mathrm{t}_{\mathrm{i}}-\mathrm{t}\right)^{2}}$

where:

$\mathrm{X}_{\text {exp }}, \mathrm{X}_{\text {calc }}$ - degree of conversion for experimental and calculated data, respectively,

$\mathrm{n}$ - number of data.

Figure 5 shows the rates of the carbonation reaction for the sorbents calcined at the three temperatures.

In Figure 5, it is noted that a very rapid and fast chemical reaction proceeds up to the degree of conversion of approximately 0.6 . The rate $\left(\mathrm{k}_{\mathrm{c}}\right)$ of this reaction has 


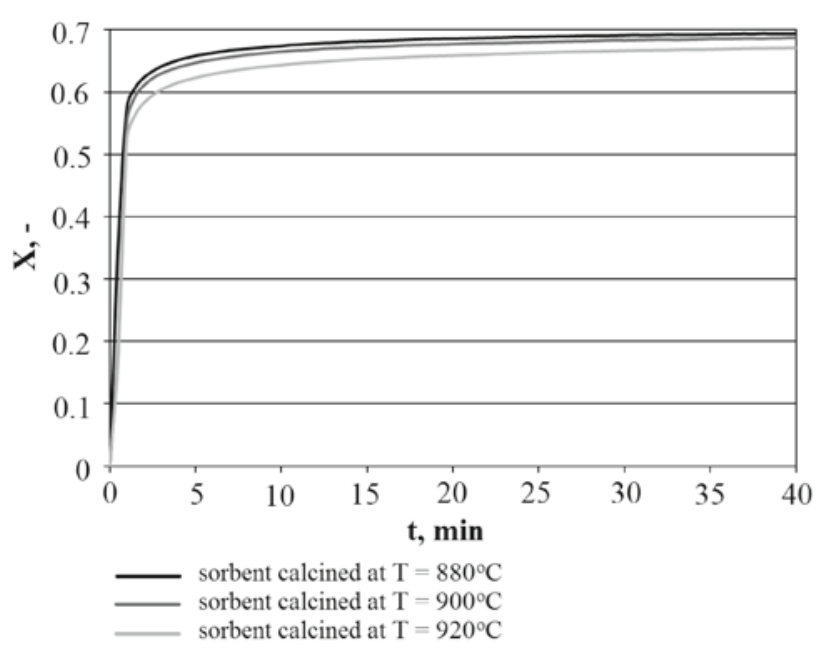

Figure 5. Degree of carbonation conversion of sorbents calcined at different temperatures as a function of time

been determined by equation (3). Above a degree of conversion of 0.6 , the reaction rate drops because of the diffusion process. Therefore, the rate $\left(\mathrm{k}_{\mathrm{c}}\right)$ of this process has been calculated using equation (4).

Equations (3) and (4) are linear and show the values from the models on the $y$ axis versus the values of time on the $\mathrm{x}$ axis. A straight line equation is obtained, and the slope equals the reaction rate. The results of the calculations conducted for sorbents calcined at different temperatures are illustrated in Figure 6.

An analysis of Figure 6 suggests that the trends of the straight lines that describe the carbonation reaction are similar regardless of the sorbent calcination temperature.
At low degrees of conversion, the reaction rate is fast. In contrast, at higher values, the reaction rate drops to nearly zero. The established reaction rates have been provided in Table 1.

The diffusion process was divided into two stages: the first took place within 2-8 minutes; the second proceeded at the reaction time above 8 minutes. The first stage is a transition stage between the chemical reactions and does not proceed as rapidly as the previous test. This suggests that the diffusion process has an increased impact on the surface reaction. The second stage is exclusively the diffusion process. As carbonation time elapses, diffusion exerts an increasingly stronger impact on the rate. Diffusion ultimately reaches the stage that completely limits the reaction. Based on these determined rates, one can conclude that the chemical reaction proceeds at the highest rate, while diffusion has a rate close to zero. The rate of the transition stage proceeds slowly yet at an order of magnitude higher than the diffusion process, which is still considerably lower than the chemical reaction rate. Therefore, it is noted that the transition zone is controlled more by diffusion limitations than the chemical reaction. In this case, the sorbent calcination temperature has no impact on the reaction rate. However, in the case of the chemical reaction, as the calcination temperature rises, the reaction rate decreases to a small extent.

Table 2 presents some kinetic rates of the carbonation of calcium oxide obtained by various researchers.

It is very difficult to compare the kinetic rate values because the shrinking core model is the general model. The other model includes many accurate parameters such
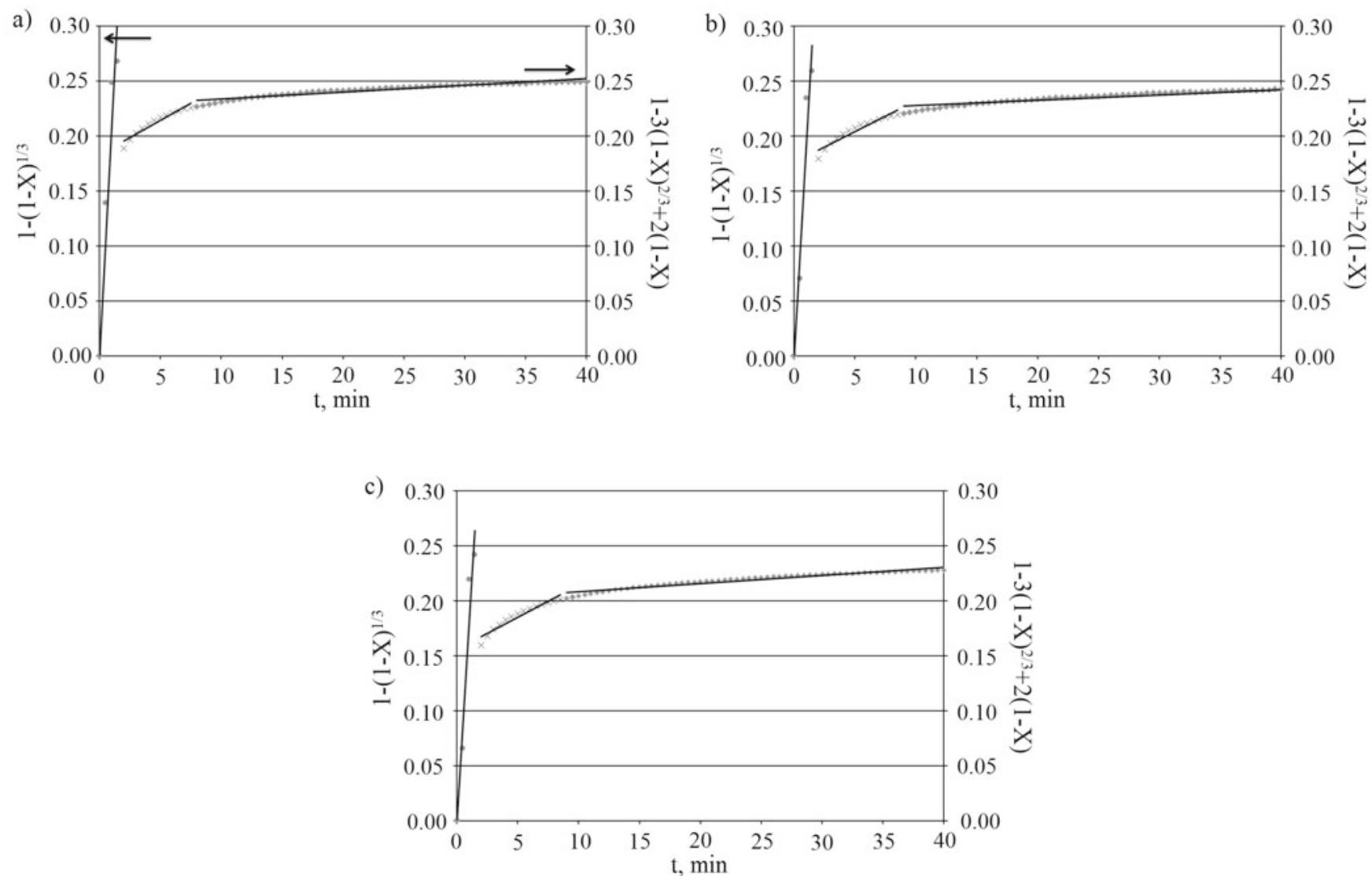

Figure 6. Linear matching of experimental carbonation data with kinetic models for sorbents calcined at: a) $\mathrm{T}=880^{\circ} \mathrm{C}$, b) $\mathrm{T}=900^{\circ} \mathrm{C}$, and c) $\mathrm{T}=920^{\circ} \mathrm{C}$ 
Table 1. Rates of sorbent carbonation calcined at different temperatures at two stages: chemical reaction and diffusion

\begin{tabular}{|l|c|c|c|}
\hline \multirow{2}{*}{ Calcination temperature $\left[{ }^{\circ} \mathrm{C}\right]$} & \multicolumn{3}{|c|}{ Reaction rate $\mathrm{k}[1 / \mathrm{min}]$} \\
\cline { 2 - 4 } & $\mathrm{k}_{\mathrm{c}}$ & $\mathrm{k}_{\mathrm{d} 1} \cdot 10^{-3}$ & $\mathrm{k}_{\mathrm{d} 2} \cdot 10^{-4}$ \\
\hline 880 & $0.206 \pm 0.044$ & $6.3 \pm 1.2$ & $6.0 \pm 0.5$ \\
\hline 900 & $0.188 \pm 0.040$ & $5.6 \pm 1.0$ & $5.0 \pm 0.5$ \\
\hline 920 & $0.176 \pm 0.034$ & $5.8 \pm 1.0$ & $7.0 \pm 0.6$ \\
\hline
\end{tabular}

$k_{c}-$ chemical reaction rate, $k_{d 1}$ - rate of diffusion in time of $2-8$ minutes, $k_{d 2}-$ rate of diffusion in time of the reaction progress above 8 minutes.

Table 2. Comparison of results obtained using different kinetic models

\begin{tabular}{|c|c|c|c|c|}
\hline Model & $\mathrm{k}_{\mathrm{c}}$ & $\mathrm{k}_{\mathrm{d}}$ & $\mathrm{T}_{\mathrm{c}}\left[{ }^{\circ} \mathrm{C}\right]$ & Reference \\
\hline Model according Lee & $\begin{array}{c}0.406 \\
0.925 \\
1.855 \\
{[1 / \mathrm{min}]} \\
\end{array}$ & $\begin{array}{c}0.049 \\
0.344 \\
2.111 \\
{[1 / \mathrm{min}]} \\
\end{array}$ & $\begin{array}{l}585 \\
655 \\
725\end{array}$ & 16 \\
\hline Model according Lee & $\begin{array}{c}0.273 \\
0.563 \\
0.858 \\
{[1 / \mathrm{min}]} \\
\end{array}$ & $\begin{array}{l}0.074 \\
0.165 \\
0.375 \\
{[1 / \mathrm{min}]} \\
\end{array}$ & $\begin{array}{l}550 \\
600 \\
650\end{array}$ & 16 \\
\hline Random pore model & \multicolumn{2}{|l|}{$3.26 \cdot 10^{-4}[\mathrm{~m} / \mathrm{min}]$} & - & 30 \\
\hline Overlapping grain model & \multicolumn{2}{|l|}{$1.0 \cdot 10^{-3}[\mathrm{~m} / \mathrm{min}]$} & - & 30 \\
\hline Random pore model & $2.1 \cdot 10^{-3}[\mathrm{~m} / \mathrm{min}]$ & $6.0 \cdot 10^{-18}-6.0 \cdot 10^{-21}\left[\mathrm{~m}^{2} / \mathrm{min}\right]$ & - & 15 \\
\hline Random pore model & $1.3 \cdot 10^{-3}[\mathrm{~m} / \mathrm{min}]$ & $4.62 \cdot 10^{-13}-1.98 \cdot 10^{-15}\left[\mathrm{~m}^{2} / \mathrm{min}\right]$ & - & 22 \\
\hline
\end{tabular}

as the length and surface area per unit volume, porosity, and pore size distribution. After taking these parameters into account, the kinetic parameters are also changed. In addition, the experimental conditions are different and that also affects the kinetic rate values. However, it can be said that rates of the chemical reaction are definitely higher than the rates of the diffusion process.

It is worth noting that this study, as described, is basic research. In the case of sorbent carbonation, some investigations, such as the determination of structural properties, are very important. Extending the range of experiments and kinetics will be the subject of further study.

\section{CONCLUSIONS}

This paper studied the impact of different process parameters on calcination and carbonation for the calcium looping process. Based on the analysed results, one can conclude that the following:

The examined calcium sorbent reaches higher carbonation conversion levels at increased carbon dioxide concentrations. This also occurs when the carbonation/ calcination cycles are greater than 5 .

The carbonation process proceeds in two main stages: the first is the surface chemical reaction, and the second is the diffusion reaction. A transition zone, which is a deviation between the chemical and diffusion stages, is also observed.

The chemical reaction proceeds at the highest rate. In contrast, diffusion proceeds with a rate close to zero. The transition stage proceeds slowly, with considerably lower rates than the chemical reaction rate. Therefore, it is noted that the stage is controlled more by diffusion limitations than the chemical reaction.

The sorbent calcination temperature has a negligible impact on the reaction rate of the chemical reaction stage and has no impact in the case of the diffusion stage of the process.

\section{ACKNOWLEDGEMENTS}

This research was conducted in the framework of the "Development of coal gasification technology for high-efficiency production of fuels and energy" project, Task No. 3 of the Strategic Programmes for Re-search and Development: "Advanced energy generation technologies" funded by the National Centre for Research and Development, Poland.

\section{LITERATURE CITED}

1. Kotyczka-Morańska, M., Tomaszewicz, G. \& Łabojko, G. (2012). Comparison of different methods for enhancing $\mathrm{CO}_{2}$ capture by $\mathrm{CaO}$-based sorbents. Review. Physicochem. Probl. Miner. Process. 48, 77-90.

2. Manovic, V. \& Anthony, E. (2007). $\mathrm{SO}_{2}$ retention by reactivated CaO-based sorbent from multiple $\mathrm{CO}_{2}$ Capture Cycles. Environ. Sci. Technol. 41, 4435-4440. DOI: 10.1021/es0629458. 3. Li,Y., Zhao, Ch., Chen, H., Liang, C., Duan, L. \& Zhou, W. (2009) Modified CaO-based sorbent looping cycle for $\mathrm{CO}_{2}$ mitigation. Fuel 88, 697-704. DOI: 10.1016/j.fuel.2008.09.018. 4. Manovic, V. \& Anthony, E. (2010a). Sulfation Performance of CaO-Based Pellets Supported by Calcium Aluminate Cements Designed for High-Temperature $\mathrm{CO}_{2}$ Capture. Energy \& Fuels 24, 1414-1420. DOI: 10.1021/ef900943h.

5. Adánez, J., de Diego, L. \& Garcia-Labiano, F. (1999). Calcination of calcium acetate and calcium magnesium acetate: effect of the reacting atmosphere. Fuel, 78, 583-592. DOI: 10.1016/S0016-2361(98)00186-0.

6. Nimmo, W., Patsias, A., Hampartsoumian, E., Gibbs, B., Fairweather, M. \& Williams, P. (2004). Calcium magnesium acetate and urea advanced reburning for NO control with simultaneous $\mathrm{SO}_{2}$ reduction. Fuel 83, 1143-1150. DOI: 10.1016/j. fuel.2003.11.011.

7. Patsias, A., Nimmo, W., Gibbs, B. \& Williams, P. (2005). Calcium-based sorbents for simultaneous $\mathrm{NO}_{\mathrm{x}} / \mathrm{SO}_{\mathrm{x}}$ reduction in a down-fired furnace. Fuel 84, 1864-1873. DOI: 10.1016/j. fuel.2005.03.009.

8. Manovic, V. \& Anthony, E. (2010b). $\mathrm{CO}_{2}$ Carrying behavior of calcium aluminate pellets under high-temperature/high- $\mathrm{CO}_{2}$ concentration calcination conditions. Ind. Eng. Chem. Res. 49, 6916-6922. DOI: 10.1021/ie901795e. 
9. Manovic, V. \& Anthony, E. (2008). Parametric Study on the $\mathrm{CO}_{2}$ Capture Capacity of CaO-Based Sorbents in Looping Cycles. Energy \& Fuels 22, 1851-1857. DOI: 10.1021/ef800011z. 10. Bouquet, E., Leyssens, G., Schönnenbeck, C. \& Gilot, P. (2009). The decrease of carbonation efficiency of $\mathrm{CaO}$ along calcination-carbonation cycles: Experiments and modelling. Chem. Eng. Sci. 64, 2136-2146. DOI: 10.1016/j.ces.2009.01.045.

11. Hughes, R., Lu, D., Anthony, E. \& Wu, Y. (2004). Improved long-term conversion of limestone-derived sorbents for in situ capture of $\mathrm{CO}_{2}$ in a fluidized bed combustor. Ind. Eng. Chem. Res. 43, 5529-5539. DOI: 10.1021/ie034260b.

12. Beruto, D., Barco, L. \& Searcy, A. (1984). $\mathrm{CO}_{2}$-catalyzed surface area and porosity changes in high-surface-area $\mathrm{CaO}$ aggregates. J. Am. Ceram. Soc. 67, 512-516. DOI: 0.1111/j.11512916.1984.tb19644.x.

13. Butler, J., Lim, C. \& Grace, J. (2014). Kinetics of $\mathrm{CO}_{2}$ absorption by $\mathrm{CaO}$ through pressure swing cycling. Fuel 127, 78-87. DOI: 10.1016/j.fuel.2013.09.058.

14. Oakeson, W. \& Culter, I. (1979). Effect of $\mathrm{CO}_{2}$ pressure on the reaction with $\mathrm{CaO}$. J. Am. Ceram. Soc. 62, 556-558. DOI: 10.1111/j.1151-2916.1979.tb12729.x.

15. Bhatia, S. \& Perlmutter, D. (1983). Effect of the product layer on the kinetics on the $\mathrm{CO}_{2}$-lime Reaction. AIChE J. 29, 79-86. DOI: 10.1002/aic.690290111.

16. Lee, D. (2004). An apparent kinetic model for the carbonation of calcium oxide by carbon dioxide. Chem. Eng. J. 100, 71-77. DOI: 10.1016/j.cej.2003.12.003.

17. Li, Z. \& Cai, N. (2007). Modeling of multiple cycles for sorption-enhanced steam methane reforming and sorbent regeneration in fixed bed reactor. Energy \& Fuels 21, 2909-2918. DOI: $10.1021 /$ ef070112c.

18. Szekely, J. \& Evans, J. (1970). Structural model for gassolid reactions with a moving boundary. Chem. Eng. Sci. 25, 1091-1107. DOI: 10.1016/0009-2509(71)86033-5.

19. Johnsen, K., Grace, J., Elnashaie, S., Kolbeinsen, L. \& Eriksen, D. (2006). Modelling of sorption-enhanced steam reforming in a dual fluidized bubbling bed reactor. Ind. Eng. Chem. Res. 45, 4133-4144. DOI: 10.1021/ie0511736.

20. Bhatia, S. \& Perlmutter, D. (1980). A random pore model for fluid-solid reactions: I. Isothermal, kinetic control. AIChE J. 26, 379-386. DOI: 10.1002/aic.690260308.

21. Bhatia, S. \& Perlmutter, D. (1981). A random pore model for fluid-solid reactions: II. Diffusion and transport effects. AIChE J. 27, 247-254. DOI: 10.1002/aic.690270211.

22. Grasa, G., Murillo, R., Alonso, M. \& Abanades, J. (2009). Application of the random pore model to the carbonation cyclic reaction. AIChE J. 55, 1246-1255. DOI: 0.1002/aic.11746. 23. Liu, W., Dennis, J. Sultan, D. Redfern, S. \& Scott, S. (2012). An investigation of the kinetics of $\mathrm{CO}_{2}$ uptake by a synthetic calcium based sorbent. Chem. Eng. Sci. 69, 644-658. DOI: 10.1016/j.ces.2011.11.036.

24. Yu, Y., Liu, W., An, H., Yang, F., Wang, G., Feng, B., Zhang, Z. \& Rudolph, V. (2012). Modeling of the carbonation behavior of a calcium based sorbent for $\mathrm{CO}_{2}$ capture. Int. J. Greenhouse Gas Cont. 10; 510-519. DOI: 10.1016/j. ijggc.2012.07.016.

25. Chen, H., Zhao, Ch., Li,Y. \& Chen, X. (2010). CO 2 Capture Performance of Calcium-Based Sorbents in a Pressurized Carbonation/Calcination Loop. Energy Fuels 24, 5751-5756. DOI: 10.1021/ef100565d.

26. Baker, E.H. (1962). The calcium oxide-carbon dioxide system in the pressure range 1-300 atmospheres. J. Chem. Soc. (464-470). DOI: 10.1039/JR9620000464.

27. Szekely, J., Evans, J.W. \& Sohn, H.Y. Gas-solid reactions. Academic Press, New York (1976).

28. Levenspiel, O. (1972) Chemical Reaction Engineering. Third ed. Wiley, New York.

29. Yagi, S. \& Kunii, D. (1955) Studies on combustion of carbon particles in flames and fluidized beds, Proceedings of 5th (int.) Symbosium on Combustion, Reinhold, New York, 231.
30. Zhou, Z., Xu, P., Xie, M., Cheng, Z. \& Yuan, W. (2013). Modeling of the carbonation kinetics of a synthetic CaObased sorbent. Chem. Eng. Sci. 95, 283-290. DOI: 10.1016/j. ces.2013.03.047. 